\title{
Seawater capacitance - a promising proxy for mapping and characterizing drifting hydrocarbon plumes in the deep ocean
}

\author{
J. C. Wynn ${ }^{1}$ and J. A. Fleming ${ }^{2}$ \\ ${ }^{1}$ Cascades Volcano Observatory, US Geological Survey, 1300 SE Cardinal Ct, Vancouver, WA 98683, USA \\ ${ }^{2}$ Zonge International, 3322 E. Fort Lowell Road, Tucson, AZ 85716, USA
}

Correspondence to: J. C. Wynn (jwynn@usgs.gov)

Received: 25 April 2012 - Published in Ocean Sci. Discuss.: 3 August 2012

Revised: 28 November 2012 - Accepted: 30 November 2012 - Published: 18 December 2012

\begin{abstract}
Hydrocarbons released into the deep ocean are an inevitable consequence of natural seep, seafloor drilling, and leaking wellhead-to-collection-point pipelines. The Macondo 252 (Deepwater Horizon) well blowout of 2010 was even larger than the Ixtoc event in the Gulf of Campeche in 1979. History suggests it will not be the last accidental release, as deepwater drilling expands to meet an ever-growing demand. For those who must respond to this kind of disaster, the first line of action should be to know what is going on. This includes knowing where an oil plume is at any given time, where and how fast it is moving, and how it is evolving or degrading. We have experimented in the laboratory with induced polarization as a method to track hydrocarbons in the seawater column and find that finely dispersed oil in seawater gives rise to a large distributed capacitance. From previous sea trials, we infer this could potentially be used to both map and characterize oil plumes, down to a ratio of less than 0.001 oil-to-seawater, drifting and evolving in the deep ocean. A side benefit demonstrated in some earlier sea trials is that this same approach in modified form can also map certain heavy placer minerals, as well as communication cables, pipelines, and wrecks buried beneath the seafloor.
\end{abstract}

\section{Introduction}

The Macondo disaster is the largest offshore oil spill in history, releasing 4.9 million barrels ( 780 million liters) into the Gulf of Mexico (Unified Command, 2010; Hsieh, 2010; Crone and Tolstoy, 2010; Ramseur, 2010). This is the latest in a long series of hydrocarbon spills, both deliberate (e.g., the Gulf War spill of 1991) and accidental, released into the world's oceans (Yapa and Chen, 2004). Where the complex hydrocarbons end up after such an event is important to scientists, policy planners, and litigants. After direct recovery, evaporation, skimming and burning, and "naturally dispersed" components are counted, the whereabouts of at least $38 \%$ of the Macondo hydrocarbons remains unknown (Ramseur, 2010). Dissolved oxygen concentrations suggest that microbial consumption rates are very low in the cold abyssal sea, on the order of 1 micromolar oxygen per day (Camilli et al., 2010). As a result, a deep plume is thought to have advected away in the Gulf Loop Current at least several hundred kilometers from the Macondo well during 2010 (Kessler et al., 2011). A towed seawater capacitance-measuring geoelectrical array could be used to map and characterize such evolving plumes in the future.

Before mitigation can be planned or liability assessed, a hydrocarbon release must be mapped in 3-D, to see how it evolves and degrades in space and time. One way to do this is by cable-lowered rosette sampling (Breier, et al., 2010) deployed from a stationary ship. However, this is slow and expensive, requires downstream mass spectrometry or subsequent chemical analysis, and provides only a narrow vertical profile sample while a plume is moving past it. Another approach utilizes a membrane inlet mass spectrometer deployed on an autonomous underwater vehicle (Camilli et al., 2010). This latter approach can detect methane concentrations down to $0.1 \mathrm{ppm}$, but like rosette profiling it is linear point-sampling, and it remains difficult to gather complete three-dimensional information. Acoustic echo soundings of the Macondo plume showed anomalously high-volume scattering at $200 \mathrm{khz}$ in one test, but this is impossible to convert into a three-dimensional quantitative image, in part because 
the method is more sensitive to the gas than the liquid oil component of the plume by several orders of magnitude (Weber et al., 2011).

\section{The induced polarization effect}

We have experimented with a galvanic geoelectrical approach based on the principle of induced polarization (IP). IP has been routinely used on land since the 1940s (Sumner, 1976) and has been used in seafloor applications since 1986 (Wynn, 1988). IP measures a distributed capacitance-like behavior observed in certain polarizing materials such as sulfides or clays beneath the Earth's surface; results are usually given as phase shift (in milliradians) between transmit and receive signals. Complex resistivity (broadband or "spectral IP") is generally measured as real and quadrature frequency components of the IP response in both lab and field settings (Zonge and Wynn, 1975).

The inducing voltage is provided by two electrodes comprising a current transmitter dipole, and receiver electrode dipole pairs are used to measure a secondary signal. In both laboratory sample cells and in the field, IP measurements are carried out using any of several different fourelectrode arrays. Results are normalized geometrically to provide two volume-independent parameters (usually resistivity and phase shift) for a polarizing material. The polarization effect is a surface-sensitive phenomenon due to any of several different electro-chemical/electro-physical mechanisms, each of which behaves like a frequency-dependent distributed capacitance (Sumner, 1976; Zonge and Wynn, 1975; Slater and Lesmes, 2002). Thus, finely disseminated target materials, in very small percentages in a host matrix or in seawater, are more easily detected (make better targets) than the same materials in a concentrated form.

While data are normalized, larger dipole separations on the surface of a half-space will nevertheless sample deeper into the underlying rock - the result is a resistivity and phase shift average for a larger volume (Sumner, 1976). However, as a four-electrode IP array is towed through the open ocean, the array will sample a cylindrical volume surrounding it as a continuous apparent resistivity and continuous phase shift. As in a land surface application, the actual volume sampled in the oceanic configuration is greater both for larger dipole length and larger transmit-receiver dipole separation, but high seawater conductivity imposes a practical upper limit (Wynn et al., 2011).

Early on, we realized that high-frequency measurements would severely attenuate our sampling distance in the deep ocean. We therefore chose to experiment only with the lower "traditional" IP frequency range $(0.1-72 \mathrm{~Hz})$. This frequency range would give us a reasonable chance of sampling a large volume of seawater rapidly enough to make this approach both realistic and achievable. We believe the physical mechanism is not dielectric in character (we see the strongest effect at very low frequencies), but instead is ion adsorption and relaxation in a double-layer effect onto the oil surface - in other words, something closely akin to Warburg impedance.

Now consider a classical capacitor with metal plates separated by an oil-based dielectric vs. droplets of oil dispersed in conductive seawater (Fig. 1). The topological equivalence suggested to us that diffuse oil in seawater should contribute a net distributed capacitance. Measurement of in-situ seawater capacitance might then serve as a proxy for hydrocarbons present as a dispersed plume in the deep ocean. Seawater by itself has an average resistivity of about 0.30 ohmmeters $\left(3.27 \mathrm{~S} \mathrm{~m}^{-1}\right)$, and no phase shift response (i.e., zero capacitance). A two-dimensional geoelectrical array (Fig. 2), using a modified form of the IP method, can sample resistivity and phase shift over a vertical cross-section or 2-D plane in the sea. Towing the array in open, unpolluted water provides a system calibration, which can then be deconvolved with survey data in the frequency domain after a simple fast Fourier transform (Wynn et al., 2011). If oil is present in the seawater column - or if sulfides, ilmenite $\left(\mathrm{FeTiO}_{3}\right)$, or metallic debris lie on or beneath the seafloor - then a non-zero capacitance manifested as a net phase shift will be observed. If the array is towed through the ocean in a lawn-mower fashion, a 3-D map of resistivity and seawater capacitance may be assembled as fast as the array can be towed through the medium. Repeat surveys would provide a 4-D mapping product; in other words, we should be able to map the evolution of the plume with time.

From sea trials in Puget Sound and off the coast of South Africa (Wynn et al., 2011), we know that such a plane-slice could sample a volume up to $40 \mathrm{~m}$ wide, and the vertical range sampled would be limited only by the number of parasitic streamers extended off the master cable of Fig. 2. A further consideration of Fig. 1 and laboratory data (discussed below) suggests that the size distribution of oil droplets in seawater also has a distinctive and characteristic frequency response. In sea trials we have also observed a phase shift along with a subtle resistivity drop over buried metallic debris (wrecks) and sub-seafloor cables.

\section{Laboratory measurements}

We have conducted laboratory experiments to measure the normalized distributed capacitance of low-concentration oilseawater emulsions, measured as a phase shift response to an inducing, time-varying voltage. This is similar to using spectral IP to detect and characterize disseminated sulfide minerals on land (Sumner, 1976; Zonge and Wynn, 1975; Sheriff, 2002), in that both processes induce a temporary distributed charge accumulation. A measurement cell was filled with seawater (Fig. 3), and multi-viscosity oil was titrated into it and stirred to force dissemination. Experiments with conductive fluids in sandstones indicate that any phase shift 


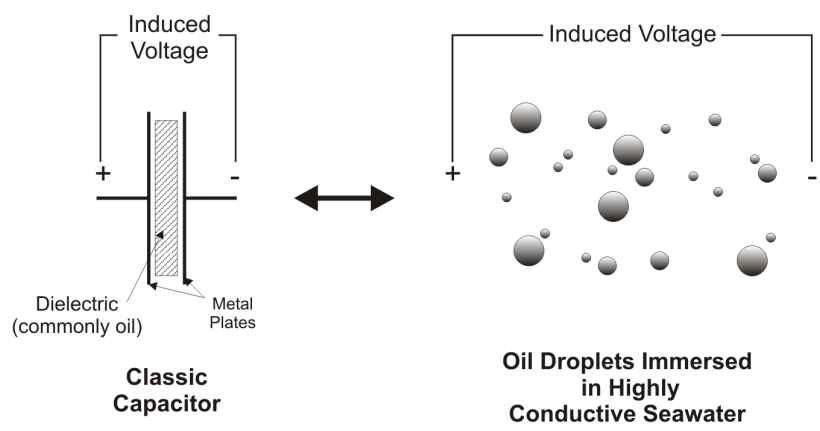

Fig. 1. The topological equivalence of a classical capacitor with an oil-based dielectric, and oil dispersed in conductive seawater, suggests that oil should display capacitive behavior under an inducing voltage from a towed geoelectrical array.

is independent of the fluid conductivity (Revil and Skold, 2011).

Laboratory results show an unusually strong phase shift for low levels of dispersed hydrocarbons in seawater (up to 460 milliradians for $3 \%$ oil/saltwater; see Fig. 4). By way of comparison, a land survey over a disseminated sulfide deposit, or a similar laboratory cell measuring a core sample from the same deposit, may give a phase shift as high as 20 milliradians. The apparent noise in frequencies below $8 \mathrm{~Hz}$ in Fig. 4 is due to the difficulty in mixing oil and seawater into a uniform and stable emulsion. We used a martini stirrer to generate the emulsion, waited for visible turbulence to end, and then made our broadband $(0.125-72 \mathrm{~Hz})$ phase shift measurements. The peaks in this figure below $8 \mathrm{~Hz}$ are caused by different macroscopic oil droplet sizes; these are transient and difficult to assess, but from photographs range from less than $1 \mathrm{~mm}$ up to about $4 \mathrm{~mm}$. The curves show a decrease in phase shift with increasing frequency; this behavior appears due to finer droplets that have a greater latency in the emulsion. As droplets slowly biodegrade in the seawater over time (Camilli et al., 2010; Kessler et al., 2011), we expect a weaker overall phase shift response, as well as a shift to higher frequencies correlating with decreased droplet size. Most of the methane in the Macondo effusion was biodegraded within 120 days (Kessler et al., 2011), and about $40 \%$ of the hydrocarbon mix released was liquid oil (Crone and Tolstoy, 2010). With the relatively slow biodegradation of the oil, $25-38 \%$ of it apparently remained in the seawater column for an extended period of time (Mariano, 2011; Camilli et al., 2010). The dispersed nature of the oil makes it an excellent target for a planar geoelectrical array optimized to measure the distributed capacitance of the seawater.

We had some concern with the inherent difficulty of achieving a stable emulsion in a small laboratory cell. Experience suggests that without the addition of emulsifiers it would be difficult to prepare a stable mixture that would be more than approximately quantifiable in terms of droplet size. This is due to steady recombination of oil droplets in

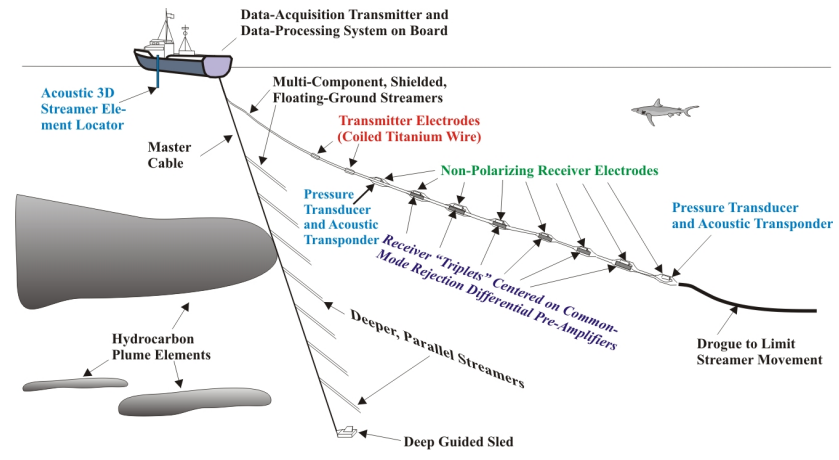

Fig. 2. One of several possible seawater capacitance-measuring configurations. A single-cable version has been used to map ilmenite $\left(\mathrm{FeTiO}_{3}\right)$ beneath the seafloor in the Gulf of Mexico, off the coast of Georgia (USA), and offshore of South Africa. This ship-towed streamer array would continuously sample a plane up to $40 \mathrm{~m}$ wide through the deep ocean, and towing the array in lawnmower fashion would quickly provide a 3-D image of the hydrocarbon plume elements. Repeat surveys would then provide information on plume movement, and by tracking frequency distribution of the transmitter-receiver phase shift, its biodegradation and evolution over time.

a bounded sample container. We are aware of optical approaches to assess sediment load in river water, but this would require some confidence that the emulsion would be at least metastable. There are other considerations, including refraction and partial transparency. From Camilli et al. (2010), we believe that in the open sea the oil-water mixture is metastable, with droplet size changing slowly as a function of biodegradation over time, after the more volatile components reach the surface.

\section{Sea trials and the noise threshold}

To establish the detection threshold of this type of approach, it is necessary to understand the noise contribution in any field measurement. Sea trials of a single-streamer IP array (a single cable version of Fig. 2), using a transmitter dipole and two receiver dipoles, were made in the Gulf of Mexico (Wynn and Laurent, 1999). The survey showed a phase shift noise envelope of about 1 milliradian when the streamer was towed at three knots (about $1.5 \mathrm{~m} \mathrm{~s}^{-1}$ ) through unpolluted seawater over apparent metallic debris (Fig. 5). This site is located in a shoal area of the Chandeleur Islands with numerous documented wrecks, and not far from an 18th century ballast pile excavated by archeologists that included six cannons (Garrison et al., 1989). The phase shift envelope in Fig. 5 shows a discrete feature with high-frequency oscillatory noise added. This noise is caused by the streaming potential: seawater passing over the electrodes, in addition to tiny tow-flexures of the array that momentarily shorten the electrode separation and decrease the apparent resistivity. These oscillations are below 0.5 milliradians outside of 


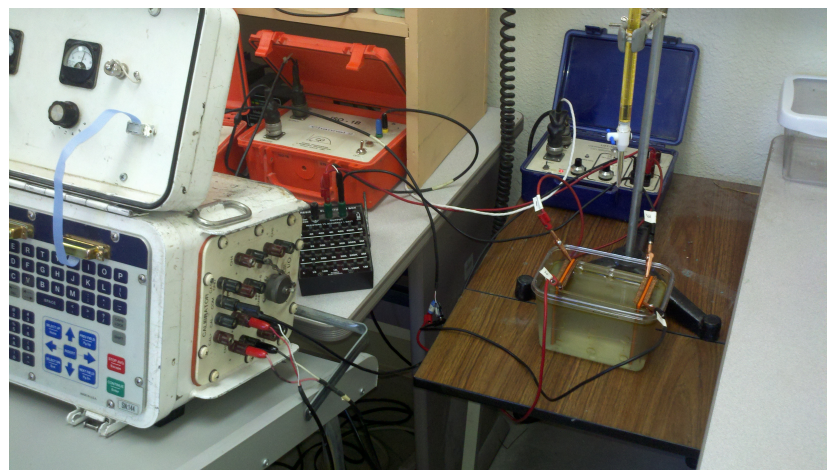

Fig. 3. The four-electrode laboratory cell used for measuring the capacitance of a multi-viscosity oil titrated into seawater. The electrodes are arranged in a modified Wenner array.

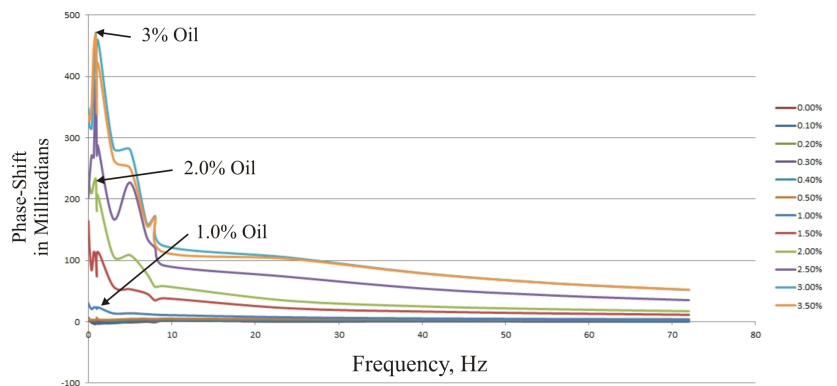

Fig. 4. Normalized distributed capacitance as a phase shift between transmit and receive signals for different multi-viscosity oil percentages dispersed in seawater. Phase shift is given in milliradians. For a $3 \%$ oil-seawater mix, the phase shift reaches about 460 milliradians at $1 \mathrm{~Hz}$. To put this in perspective, a large IP anomaly over a disseminated sulfide orebody on land, or a core-sample of this material in the laboratory, might reach 20 milliradians.

the metallic anomaly. In Fig. 4, a $1 \%$ oil content contributes a phase shift of at least 10 and up to 23 milliradians. Assuming a conservative noise threshold of 1 milliradian and a minimum 10 milliradians for $1 \%$ oil in seawater, it appears that a modified version of the streamer towed in the deep ocean could detect hydrocarbons in seawater down to below $0.1 \%$. The real noise threshold could be lower depending on engineering considerations, such as careful management of shipboard electrical noise. The conservative $0.1 \%$ oil-toseawater detection threshold is orders of magnitude less sensitive than the detection threshold of a membrane inlet mass spectrometer, approximately $0.1 \mathrm{ppm}$ for methane in seawater (Camilli et al., 2010; Hemond, et al., 2008). However, this seawater capacitance approach can map the distribution and even characterize liquid hydrocarbons by droplet size in 3 dimensions as fast as a 2-D array can be towed through the sea.

Broadband measurements (a single square-wave signal that is then Fourier transformed to magnitude and phase values over a broad frequency range) should be conducted at

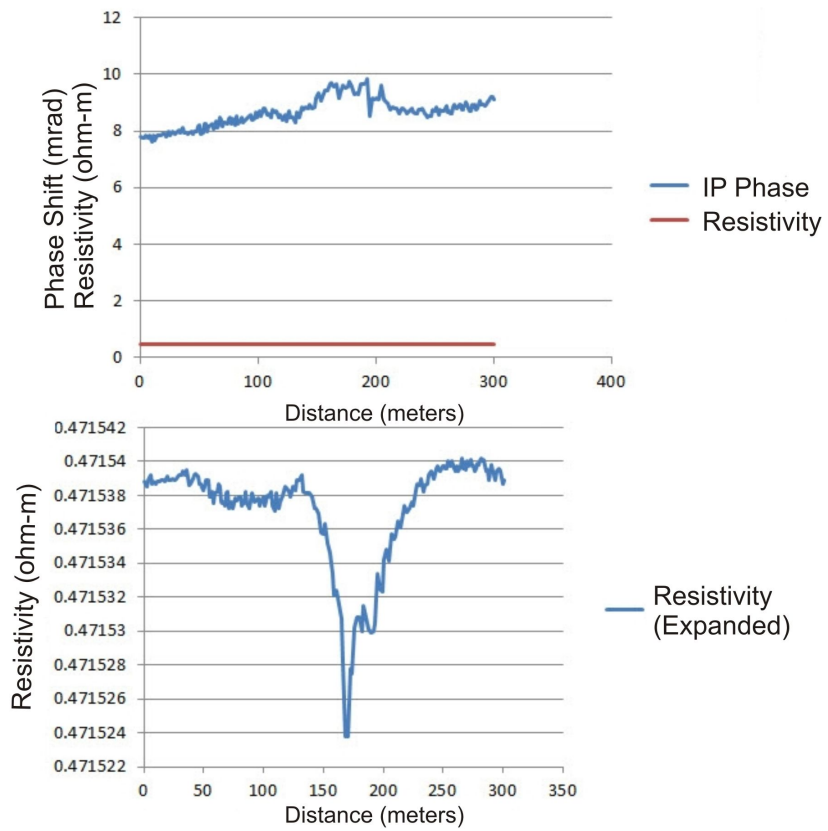

Fig. 5. The resistivity and phase shift (IP) signature of buried metallic debris east of Cat Island, south of Biloxi, MS, in the Gulf of Mexico. The resistivity here is higher than the seawater average due to the cable being towed directly on the water-seafloor interface.

minimal speed in the sea. This is necessary to permit the effective transmission of low-frequency waveforms to detect the largest oil droplets in seawater. We want to know where the plume is moving and how much oil is involved, as well as characterize how it biodegrades and disperses, and broadband measurements are key to the latter. An important source of potential noise is electromagnetic coupling, but with a fixed array in deep water this should be constant. In shallow water this will not be the case; thus geometric corrections must be made to minimize its contribution in shallow coastal waters (Wynn et al., 2011).

A seawater capacitance detection system, however, reacts to the surface area between oil and seawater, so it would be proportionally more sensitive to the finely dispersed oil reported in the Macondo plume (Camilli et al., 2010). A towedarray seawater capacitance survey can also be conducted very efficiently in the deep ocean. Multi-frequency measurements are typically made $1-4$ times per second for each parasitic streamer, each with a transmitter dipole and multiple receiver dipole pairs. The sample spacing is proportional to ship speed and transmitter frequency. Repeat surveys should provide a 4-D map of a moving hydrocarbon plume, as well as characterize the plume (using droplet-size change as a proxy for biodegradation) as it moves and evolves with time. Marine IP systems have been shown to detect ferrous and non-ferrous material, including both wrecks and fiber-optic cables buried beneath the seafloor (Wynn and Laurent, 1999; Wynn et al., 2011). The same IP system used to map dispersed oil can 
also be used to locate buried pipelines or other metallic oil and gas infrastructure buried in the seabed.

Metallic debris and buried cables appear as point or line features. Unless the streamer is traveling sub-parallel to a buried cable, these give rise to fairly narrow phase-shift anomalies. Seawater capacitance from dispersed oil, however, would likely manifest as a slow rise of phase shift from zero to a relatively steady non-zero amount, followed by a decline as the streamer exits the dispersed plume. Ponded oil on the seafloor would manifest as a broad, non-zero phase shift with a relatively sharp onset, as long as the streamer was traversing it. The amplitude of the phase-shift response would be a function of the oil-to-seawater surface area within sensing reach of the array. From experimental sea trials, this phase shift will likely not be detected beyond about $20 \mathrm{~m}$ due to signal attenuation in the conductive seawater medium.

Another issue to consider is the influence of other substances on the received signal. Up to $3800000 \mathrm{~L}$ of Corexit were eventually dropped into the Gulf of Mexico to act as a dispersant during the Deepwater Horizon blowout episode. We could find little published on the effect the Corexit had on the Deepwater Horizon hydrocarbons. While this is an interesting variable in the mapping process, the Corexit used in the Deepwater Horizon spill was delivered by aircraft and surface ships against a hydrocarbon release that began at $1260 \mathrm{~m}$ water depth. Consequently, it impacted only the more volatile components of oil that quickly reached the sea surface, but it likely had little or no effect on the larger component of the plume drifting south from the wellhead with the Gulf Loop current. Our proposed streamer system is applicable in areas and depths where we believe the Corexit would have little if any effect. Any contribution from dispersants would likely be to increase the peak phase-shift frequency upwards as the oil droplets were reduced in size.

\section{Conclusions and discussion}

Finely dispersed oil contributes a strong net capacitance to seawater when a galvanic current is introduced. In laboratory measurements this contribution, measured as a transmitterreceiver phase shift, is more than an order of magnitude greater than similar measurements made on land over mineral deposits and in laboratory cores derived from these deposits. The degradation of an oil plume with time will manifest as an upward shift in the broadband frequency distribution of this capacitance, which serves as a proxy for the oil droplet size. Because electrodes are towed in the seawater medium - an impossibility on land - this kind of measurement can be made very rapidly in seawater.

In sea trials and laboratory experiments, we have observed that certain heavy placer minerals (pyrite, ilmenite, etc.), buried wrecks, pipelines, and communications cables also manifest a capacitive behavior to an inducing galvanic current injected into the seawater.
The Gulf of Mexico hosts nearly 4000 offshore platforms currently operating, and as many as 7000 platforms have been in place since the early 20th century (N.O.A.A., 2012; National Geographic, 2010). A massive array of poorly mapped, sometimes-buried pipelines links all these offshore sites to coastal gathering points. Most of these pipelines were laid in a pre-GPS era and could reasonably be expected to corrode with time. A seawater capacitance or marine IP array can easily detect and map these pipelines, ferrous or nonferrous, even if they are buried beneath several meters of inert sediment (Wynn and Laurent, 1999; Wynn and Zonge, 1975). A multi-cable geoelectrical array can also map hydrocarbon seeps, both natural and those escaping from these pipelines, as they disperse from their sources.

Acknowledgements. This study was supported by a Cooperative Research and Development Agreement funded by the US Geological Survey, Williamson \& Associates, and Zonge International. We thank the Mississippi Mineral Resources Institute for providing ship-time on the R/V Kit Jones for the Gulf of Mexico towed-streamer experiments, and N.O.A.A. and Coastal Carolina University for providing ship-time on the R/V Ferrell for the Atlantic Continental Shelf experiments. Richards Bay Mining Company funded the survey off the coast of South Africa. The authors thank Dan Dzurisin, Norm Carlson, Scott Urquhart, and Mike Williams for discussions and helpful suggestions on the manuscript, as well as Peter Swarzenski, Jim Kauahikaua, and John Ewert of the USGS, and Don ("Skip") Snyder and another anonymous individual for technical reviews. The authors also thank Eric Delhez and Natascha Toepfer of Copernicus for their assistance and support during the Discussion part of the review.

Edited by: E. J. M. Delhez

\section{References}

Breier, J. S., Rauch, C. G., McKartney, K., Toner, B. M., Fakra, S. C., White, S. N., and German, C. R.: A suspended-particle rosette multi-sampler for discrete biogeochemical sampling in low-particle-density waters, Lawrence Berkeley National Laboratory Paper LBNL-3586E, 11 pp., 2010.

Camilli, R., Reddy, C. M., Yoerger, D. R., Van Mooy, B. A. S., Jakuba, M. V., Kinsey, J. C., McIntyre, C. P., Sylva, S. P., and Maloney, J. V.: Tracking hydrocarbon plume transport and biodegradation at Deepwater Horizon, Science, 330, 201-204, 2010.

Crone, T. J. and Tolstoy, M.: Magnitude of the 2010 Gulf of Mexico oil leak, Science, 330, 6004, doi:10.1126/science.1195840, 2010).

Garrison, E. G., Giammona, C. P., Jobling, J., Tripp, A. R., Weinstein, E. N., and Wolff, G. A.: An Eighteenth-Century Ballast Pile Site, Chandeleur Islands, Louisiana: An Instrumental and Archaeological Study, Outer Continental Shelf Region, Minerals Management Service Report 89-0092, 1989.

Hemond, H. F., Mueller, A. V., and Hemond, M.: Field testing of lake water chemistry with a portable and an AUV-based mass spectrometer, J. Am. Soc. Mass Spec., 9, 1403-1410, 2008. 
Hsieh, P.: Computer simulation of reservoir depletion and oil flow from the Macondo well following the Deepwater Horizon blowout, US Geological Survey Open-File Report 2010-1266, 118, 2010.

Kessler, J. D., Valentine, D. L., Redmond, M. C., Du, M., Chan, E. W., Mendes, S. D., Quiroz, E. W., Villanueva, C. J., Shusta, S. S., Werra, L. M., Yvon-Lewis, S. A., and Weber, T. C. A.: Persistent oxygen anomaly reveals the fate of spilled methane in the deep Gulf of Mexico, Science, 331, 312-315, 2011.

Mariano, A. J., Kourfalou, V. H., Srinivasan, A., Kang, H., Halliwell, G. R., Ryan, E. H., and Roffer, M.: On the modeling of the 2010 Gulf of Mexico oil spill, Dynam. Atmos. Oceans, 52, 322-340, 2011.

National Geographic Magazine: The geography of offshore oil, http://ngm.nationalgeographic.com/2010/10/gulf-oil-spill/ gulf-map-interactive.html (last access: April 2012), 2010.

N.O.A.A.: Oil platforms in the Gulf of Mexico, http: //oceanexplorer.noaa.gov/explorations/06mexico/background/ oil/media/platform_600.html, last acess: April 2012.

Ramseur, J. L.: Deepwater Horizon oil spill, the fate of the oil, Cong. Res. Serv., 1-20, R41531, 2010.

Revil, A. and Skold, M.: Salinity dependence of spectral induced polarization in sands and sandstones, Geophys. J. Int., 187, 813824, 2011.

Sheriff, R. E.: Encyclopedic dictionary of applied geophysics, Society of Exploration Geophysicists, University of Houston, p. 188, 2002.

Slater, L. D. and Lesmes, D.: IP interpretation in environmental investigations, Geophysics, 67, 77-88, 2002.

Sumner, J. S.: Principles of induced polarization for geophysical exploration, Elsevier, 277 pp., 1976.
Unified Command Deepwater Horizon: U.S. scientific teams refine estimates of oil flow from BP's well prior to capping, online att: www.deepwaterhorizonresponse.com/go/doc/2931/840475/, 2010.

Weber, T. C., De Robertis, A., Greenaway, S. F., Smith, S., Mayer, L., and Rice, G.: Science Applications in the Deepwater Horizon Oil Spill Special Feature, Estimating oil concentration and flow rate with calibrated vessel-mounted acoustic echo sounders, P. Natl. Acad. Sci. USA, published ahead of print 13 December 2011, doi:10.1073/pnas.1108771108, 2011.

Wynn, J. C.: Titanium geophysics - a marine application of induced polarization, Geophysics, 53, 386-401, 1988.

Wynn, J. C. and Laurent, K. W. Mapping buried metallic objects and titaniferous placers in the Mississippi Sound, Gulf of Mexico: SAGEEP Proceedings Volume 99, Symposium for Applications of Geophysics to Environmental and Engineering Problems, Oakland, CA, 803-810, 1999.

Wynn, J. C. and Zonge, K. L. Electromagnetic coupling, its intrinsic value, its removal, and the cultural coupling problem, Geophysics, 40, 831-850, 1975.

Wynn, J. C., Williamson, M., Urquhart, S., and Fleming, J. A.: An open-water electrical geophysical tool for mapping sub-seafloor heavy placer minerals in 3D and migrating hydrocarbon plumes in 4D, Proceedings of the IEEE-Marine Technology Society annual meeting, Waikaloa, HI, 19-22 September 2011, 6 pp., 2011.

Yapa, P. D. and Chen, F.: Behavior of oil and gas from deepwater blowouts, J. Hydraul. Eng. 130, 540-553, 2004.

Zonge, K. L. and Wynn, J. C.: Recent advances and applications in complex resistivity measurements, Geophysics, 40, 851-864, 1975. 